International Journal of Engineering \&Technology, $7(1.7)(2018)$ 189-193
International Journal of Engineering \& Technology
SPC
Website: www.sciencepubco.com/index.php/IJET
Research paper

\title{
Efficient utilization of energy consumption in cloud environment
}

\author{
G.Soniya Priyatharsini ${ }^{1 *}$, N.Malarvizhi ${ }^{2}$ \\ ${ }^{1}$ Research Scholar, Dept of CSE, Vel Tech Rangarajan Dr.Sagunthala R\&D Institute of Science and Technology \\ ${ }^{2}$ Professor, Dept of CSE, Vel Tech Rangarajan Dr.Sagunthala R\&D Institute of Science and Technology \\ *Corresponding author E-mail: sonigeorge85@gmail.com
}

\begin{abstract}
In the tremendous growth of the cloud computing, server consolidation plays a vital role. It gives more benefits also it gives the pollution towards the nature. Inspite of avoiding this, saving of energy in the data center or the cluster is more important. In this regard this paper proposes a method of which reduces the energy consumption. This is done by identifying the active physical machines and the remaining machines were kept in the sleep or off mode according to the user's availability. Here Virtual Machines (VMs) are grouped under the particular types. Based on this type the customer's resource request can be maintained.
\end{abstract}

Keywords: Energy efficient, Power consumption, Green Cloud.

\section{Introduction}

Cloud computing is taking large part in the computing industry nowadays. The services provided by these cloud providers are very much useful for the data users in the internet. The evolution process of the cloud is shown in the Table 1. Even though the cloud computing provides many trends through virtualization to its customers, it also very important to develop the cost effectiveness in cloud.

Table 1: Evolution process of cloud computing

\begin{tabular}{|c|c|c|c|}
\hline $\begin{array}{l}\text { Cloud Com- } \\
\text { puting }\end{array}$ & $\begin{array}{c}\text { Software as a } \\
\text { service }\end{array}$ & $\begin{array}{l}\text { Utility Compu- } \\
\text { ting }\end{array}$ & $\begin{array}{l}\text { Grid Compu- } \\
\text { ting }\end{array}$ \\
\hline $\begin{array}{l}\text { Internet com- } \\
\text { puting of next } \\
\text { generation. } \\
\text { Next data } \\
\text { center. }\end{array}$ & $\begin{array}{l}\text { Based on the } \\
\text { web reserva- } \\
\text { tion applica- } \\
\text { tion. Proposed } \\
\text { in } 2001 .\end{array}$ & $\begin{array}{l}\text { Computing } \\
\text { resources are } \\
\text { provided as } \\
\text { service that can } \\
\text { be measured. } \\
\text { Proposed in } \\
\text { 1990s. }\end{array}$ & $\begin{array}{l}\text { Uses parallel } \\
\text { computing to } \\
\text { solve large-scale } \\
\text { problems. Glo- } \\
\text { bus alliance } \\
\text { makes it the } \\
\text { main trend. }\end{array}$ \\
\hline
\end{tabular}

The cloud computing resources are distributed more widely. Thus the data center is not limited. But it can extend the number of its geographic locations. The resource utilization of the cloud is improved by the use of the virtualization. Unlike the grid or parallel computing the cloud computing is very much focus on the resources. The user don't need to focuses on the resource management in cloud. Thus for the cloud provider it is important to manage the physical and virtual machines and its resources [1]. It's their work to maintain the resources available according to the user's request. They also have to maintain the cost effectiveness, so that the user cannot switch their cloud provider. There are some obstacles in the cloud computing [2]. They are listed below in the Table 2 .
Table 2: Problems in Cloud Computing.

\begin{tabular}{|c|c|c|}
\hline & Problems & Options \\
\hline 1 & $\begin{array}{l}\text { Data Confidentiality and } \\
\text { Auditability }\end{array}$ & $\begin{array}{l}\text { Firewalls should be strictly } \\
\text { maintained }\end{array}$ \\
\hline 2 & High power consumption & Green cloud \\
\hline 3 & Availability of Service & $\begin{array}{l}\text { Multiple Cloud Providers can } \\
\text { be used }\end{array}$ \\
\hline 4 & Data Lock-In & Standardize APIs can be used \\
\hline 5 & Software Licensing & $\begin{array}{l}\text { Licenses can used as pay per } \\
\text { use }\end{array}$ \\
\hline 6 & Scaling Quickly & Auto Scaler should be used \\
\hline 7 & Performance Unpredictability & $\begin{array}{l}\text { Virtual machine support can be } \\
\text { improved }\end{array}$ \\
\hline 8 & Scalable Storage & $\begin{array}{l}\text { Proper store for scaling can be } \\
\text { used }\end{array}$ \\
\hline 9 & Reputation Fate Sharing & Reputation guard can be used \\
\hline
\end{tabular}

Even though there are many problems in the cloud computing, this work concentrates on the power usage in cloud computing. There are some of the issues which affect the global warming system. Cloud power system plays one of the main roles in affecting this global system. Huge numbers of computer are used in the data centers. These electronic devices release hazardous gases whenever they are used. They also consume high power consumption.

There are some of the basic solutions for reducing the power consumption. By practicing it in daily basic can save some small amount of energy. The practices are:

- After using the computer system turn off it.

- For using long time mode the power saving mode can be enabled.

- For the input and output devices the sleep mode can be used. 
- $\quad$ Standby mode for machines and hibernate mode.

Youseff et al.[3] presents a ontology in detail about the cloud computing by dissecting in five layers. Those five layers are the hardware (HaaS), the software kernel, Cloud software infrastructure (IaaS), Cloud software environment (PaaS) and the Cloud applications (SaaS). He also explains the interdependence and the interrelations of the five layers. In this paper, the [IaaS] Infrastructure as a service is focused. The aggregation of software distribution, allocating, and storage of network resources are granted by the Cloud computing. The virtualized resources, the hiding of the complexity, the abstraction and the efficient use of the resources are the some of the benefits of the cloud computing. Jing et al. [4] illustrates the main 3 research areas in cloud computing which is based on the green cloud. Beloglazov et al. [5] provides a survey and a energy efficient taxonomy in the cloud computing data centers.

There are some approaches where the energy efficient cloud computing can efficiently followed. They are,

- Server terminals

- Server allocation which is resourceful

- New datacenter cooling methods

- Recycling the E-waste

- VoIP

- Algorithmic productivity

- Green data centers

Here in this paper the algorithmic productivity is taken to extract maximum output for the energy consumption. From the cloud customer's perspective, they have to use the resources in the cloud as pay per use. Whenever they need the data in cloud they can login through internet and can able to use their data. With respect to the cloud provider the data is used by the customer when he logs in. But the VM allocated for the user should be available at all time. Thus by reducing the busy time cost of the energy can be reduced. In this paper to minimize the energy consumption the method for scheduling the VMs is proposed.

\section{Literature Review}

Cloud computing faces many challenges in energy efficiency. The VM allocation and the migration are the important factors considered here. The interrelationship between the power consumption, performance of consolidated workloads and the resource utilization can be explained by Srikantaiah et al [6].

Liu et al [7] examined the energy modeling and the performance of the live migrations of the VMs and evaluate the models using 5 representative workloads. By consolidating the active tasks, the resource energy efficient utilization can be improve by two online algorithms as provided by Lee et al. [8].

Beloglazov et al.[9] minimized the total number of migrations through modified algorithm of bin packing in best fit heuristics by considering the offline allocation to VMs. Mathew et al.[10] proposed for a content delivery an optimized online and offline algorithm for content delivery network by combining energy efficiency and load balancing.

Lin et al [11] designed an offline and online algorithm by turning off the idle servers in the data centers to minimize the total cost. Even though some lack of research is there in this area. Meritzios et al.[12] proposed an identical method which is considered with various special cases. They mainly focus on the throughput maximization and the total minimization of busy time problems, while this paper focuses on cloud data center energy efficiency. Amit et al[13] proposed an algorithm for the energy efficient in cloud. It states that when comparing with the round robin and the first come first serve, the task is based on size. The MIPS of the resources are compared with each other. The resource carrying the maximum MIPS can be given more priority. By doing this the heavy work will be completed easily and then the power consumption can be automatically reduced.
Guarang et al[14] introduced an algorithm which is the modified load balanced algorithm. It uses the min-min theory for the energy efficient techniques. It compares the load balancing algorithm and gives the more makesspan when comparing with it.

The remaining content of this paper explains the proposed method for energy efficient in the cloud computing. Then it compares with existing methods and the results and discussion is explained. Finally the conclusion of the work is given.

\section{Proposed Work}

In this section, to address the existing problem, a structure is introduce for the real time energy efficient scheduling of real time VM considering fixed processing intervals. The main focus is on the identification of the active physical machines with respect to that of the customer's usage. In this work following Table 3 explains the Average availability of the types of VMs. A datacenter or a cluster is the group of hosts (PMs). Here a hypervisor is there to take care of this working principle of the VMs which are present in the PMs. The proposed hypervisor Resource hypervisor and efficient allocator manages with the PM and VM model types.

Table 3: Types of VMs considered

\begin{tabular}{|l|l|l|l|l|}
\hline $\begin{array}{l}\text { VM } \\
\text { Types }\end{array}$ & $\begin{array}{l}\text { Memory } \\
(\mathbf{G B})\end{array}$ & $\begin{array}{l}\text { Storage } \\
(\mathbf{G B})\end{array}$ & Units & Name \\
\hline $1-1(1)$ & 1.875 & 211.25 & 1 & $\mathrm{~m} 1$. small \\
\hline $1-2(2)$ & 7.5 & 845 & 4 & m1.large \\
\hline $1-3(3)$ & 15.0 & 1690 & 8 & m1.xlarge \\
\hline $2-1(4)$ & 17.1 & 420 & 6.5 & m2.xlarge \\
\hline $2-2(5)$ & 34.2 & 845 & 13 & m2.2xlarge \\
\hline $2-3(6)$ & 68.4 & 1690 & 26 & m2.4xlarge \\
\hline $3-1(7)$ & 1.7 & 422.5 & 5 & c1.medium \\
\hline $3-2(8)$ & 7.0 & 1690 & 20 & c1.xlarge \\
\hline
\end{tabular}

From the VMs considered it is important to focus on the identification of the active PMs and the VMs to be migrated. Firstly to identify the active physical machines, the physical machines can be grouped in three types on the basis of the divisible configuration. The PMs clustered on the basis of the division is given in the following Table 4.

Table 4: Configuration settings of the PMs

\begin{tabular}{|l|l|l|l|}
\hline $\begin{array}{l}\text { PM } \\
\text { Types }\end{array}$ & Storage (GB) & Memory (GB) & Units \\
\hline Type 1 & 3380 & 30.0 & 16 \\
\hline Type 2 & 3380 & 136.8 & 52 \\
\hline Type 3 & 3380 & 14.0 & 40 \\
\hline
\end{tabular}

The random configuration of the same available VMs can be listed in the following Table 5.

\begin{tabular}{|c|c|c|c|}
\hline PM Types & Storage (GB) & Memory (GB) & Units \\
\hline Type 1 & 3000 & 37.0 & 13 \\
\hline Type 2 & 4000 & 137.8 & 53 \\
\hline Type 3 & 2000 & 17.0 & 47 \\
\hline
\end{tabular}

By clustering the PMs like this, in a PM with 2 X 1690 GB storage, 16 cores X 3.25 units and 2 X 68.4GB memory can be provisioned. By doing this clustering, a uniform view of the different types of VMs can be possibly done. This gives benefit in VM allocation and management. Cloud users can select the resources according to their need. 


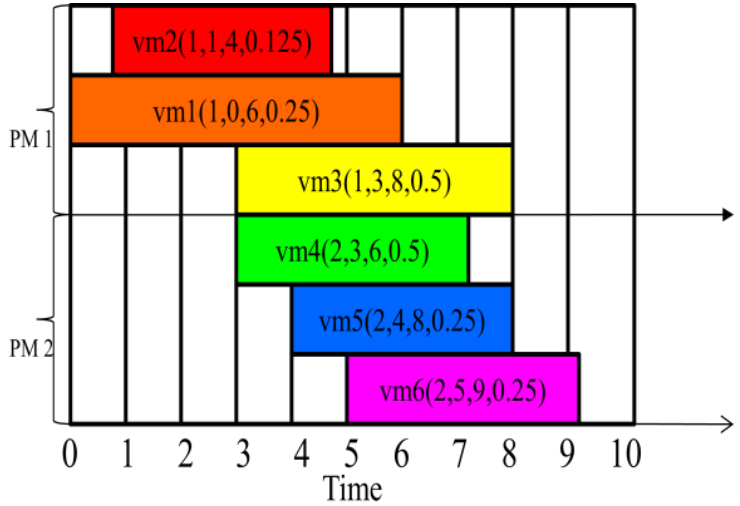

Figure 1: VM allocations using 2 PMs

The cloud user's VM request can be represented as follows: vm_Request_ID(vm type_ID, started_time, finished_time, requested_capacity). In the Figure $1 \mathrm{vm}$ allocations are given. Here the VMRequestID are represented for $6 \mathrm{VMs}$ in 2 PMs. Considering vm_1 $(1,0,6,0.25)$, the request_ID of vm_1, its type is Type 1 . The started time is $0 \&$ the finished time is 6 .It completed in the 6th slot. It also consumes 25 percent of the capacity in total of the Type 1 server. Considering vm_4(2,3,6,0.5), the request ID of vm4, its type is Type 2 . The start time is 3 and the finish time is 6.It finished in the 6th slot. It also consumes $50 \%$ of the capacity in total of the Type 2 PM. Thus another request may also be sketched in these same directions. Figure 1 explains in detail about the life cycle of the VM allocations. This happens in the time slotted format with the help of 2 PMs. PM1 manages $\operatorname{VM}(1,2,3)$. PM2 manages $\operatorname{VM}(4,5,6)$.

Many of the datacenter power consumption are from the networking, disk storage, cooling systems and the computation processing. [13] The usage of the minimum number of the active PMs and the minimized running time of severs are the main goal for an energy efficient scheduling. It can be considered with the following assumptions:

- All the user requests are independent

- All the instances are independent. So the start time and the finish time may vary.

- To satisfy the user's request, it is a positive real numbers between 0 and 1 .

- $\quad$ Each VM should be allocated to the Single PM. Thus migration will be easier compared to others.

- PM should be available at any time of the user's request.

- Considers and allocate maximum consumption of the user's request.

A power consumption server model has been implemented by Economou et al.[14]:

$$
\begin{gathered}
P=14.45+(3.1 E-8) \text { Unet }+(4.47 E-8) \text { Umem }+ \\
0.236 \text { Ucpu }++0.0028 \text { Udisk }
\end{gathered}
$$

Here $U_{\text {net }}, U_{\text {mem }}, U_{\text {cpu, }} U_{\text {disk }}$ and are the utilization of the network, memory, CPU, Harddisk respectively. The factors like network interface, hard disk and memory impacts very small amount of power consuming. Beloglazov et al.[15] implements a model that is the utilization of the CPU is directly proportional to the overall system load is given as follows:

$P(u)=k \mathrm{P}_{\operatorname{maxi}}+(1-k) \mathrm{P}_{\operatorname{maxi}} u$

Where $\mathrm{P}_{\operatorname{maxi}}$ means the power utilized in maximum level when complete server is occupied. The power consumed by the idle server's fraction is denoted as $\mathrm{k}$. The utilization of the CPU is identified as $u$.
This Proposed model targets to the power consumption of the CPU. While compared to the other resources [16] utilization of the CPU plays a vital role. With the help of the power model (2) the equation is again shortened to (3).

$\mathrm{P}=\mathrm{P}_{\min i}+\left(\mathrm{P}_{\operatorname{maxi}}-\mathrm{P}_{\text {mini }}\right) U$

When the the consumption of power of PM is given as $\mathrm{P}_{\min i}$ with 0 as the utilization of CPU. Here the PMs are not in active positions. When the CPU starts utilized the time of the workload varies. Thus $\mathrm{u}(\mathrm{t})$ is represented as utilization of the time period. The total consumption of the power of a period of time can be given as follows:

$\mathrm{E}_{i=\int_{t 0}^{t 1} P(u(t)) d t}$

Here the utilization average is explained as $\mathrm{u}(\mathrm{t})$ is $\mathrm{u}$. where $\mathrm{u}(\mathrm{t})$ is the time constant. Then $\mathrm{E}_{i=} \mathrm{P}(\mathrm{t} 1-\mathrm{t} 0)(\mathrm{u})$. The energy consumption of the data center in total is given just as:

$\mathrm{E}_{\mathrm{Total}}=\sum_{i=1}^{n} E i$

The gross of the consumption of the energy with respect to all of the PMs present in the data center which also includes the VMs. During the testing period the entire length of power on time for total PMs are given as:

TotalPowerTime $=\sum_{i=0}^{n}$ PMiPowerontime

The total power on time in the $\mathrm{i}^{\text {th }} \mathrm{PM}$ is denoted here asPMiPowerontime. Consider the situation of the VM consuming $100 \%$ of CPU request. Then the utilization of the CPU is given as $\mathrm{u}$ in the initialized stage. After the VM allocation then the CPU utilization become u'. EVM is the increased energy because of the VM:

$$
\begin{aligned}
& E_{V M}=P \times\left(t_{1}-t_{0}\right)-P^{\prime} \times\left(t_{1}-t_{0}\right) \\
& =\left(P^{\prime}-P\right) X\left(t_{1}-t_{0}\right) \\
& =\left(P_{\operatorname{mini}}+\left(P_{\operatorname{maxi}}-P_{\operatorname{mini}}\right) u^{\prime}-\left(P_{\min }-\left(P_{\max }-P_{\min }\right) u\right)\right)\left(P_{\max }-P_{\min }\right) X \\
& \left(u^{\prime}-\mathrm{u}\right) X(t 1-t 0)\left(P_{\max }-P_{\min }\right) X \Delta u X(t 1-t 0)
\end{aligned}
$$

Considering a PM is switched off at the time of the testing period. This situation is used for the calculation and reduction of the energy consumption. The testing period with start and finish time is given as 0 and 1000 . With the 3 time intervals of start time $(2,209,235)$ and the finishing time $(100,235,1000)$ a $P M$ is turned on. The utilization average to all the intervals is 0.5 . $\mathrm{P}_{\max }$ $=300 \mathrm{~W}, P_{\min }=200 \mathrm{~W}$. The power on time's entire length can be calculated as $100-2+235-209+1000-789=335$ slots.

Consider 5minits for each slot. Then energy consumption in overall can be obtained as $(200+(300-200)$ X0.5) X335 $\mathrm{X} 5 / 60 / 1000=6.979 \mathrm{kWh}$.

Minimizing total number of active PMs is one of the reasons here to minimize the power consumption. Along with this one more condition is there by turning sleep mode of the PMs and not in idle position.

Considering this condition, Servers in idle state consumes power $\mathrm{P}_{\text {min. }}$ It is never switched off. Now 1000 slots can be given as power on time. The average utilization is $335 \mathrm{X}(0.5 / 1000)=$ 0.1675 . The overall consumption of the energy can be calculated as $(200+300-200) \times 0.1675) \times 1000 \times 5 / 60 / 1000=18.06 \mathrm{kWh}$. Thus it is explained as the different usage of active servers and idle servers by using this model affects the energy consumption in total. This model uses the modified Enhanced cloud resource provisioning technique. Firstly it arranges the VMs based on utilization of their CPU in the decreasing order. There will be small variation in consumption of power due to the VM allocation.

The proposed algorithm for reducing power consumption is given below: 
The proposed algorithm for reducing power consumption is given below:

I/O : Requested capacity, Start time, Finish time, VM ID, Time interval.

O/P: Allocated time intervals for all requests.

Arrange time intervals by ST in increasing order

Let $\mathrm{I}_{1}, \mathrm{I}_{2}, \ldots \mathrm{I}_{\mathrm{n}}$ express the time interval

$\mathrm{D}=0$;

for $\mathrm{j}=1 \rightarrow \mathrm{n}$ do

foreach $I_{i}$ in the arranged order

if (overlap/not overlap $\rightarrow$ can do resource share ) do allot $\mathrm{I}_{\mathrm{i}}$ to the PM hosts Ii

else assign a new machine

$\mathrm{d}=\mathrm{d}+1$

allot $\mathrm{I}_{\mathrm{j}} \rightarrow \mathrm{d}^{\text {th }} \mathrm{PM}$

end

endeach

endfor

From this it is concluded that the consumption of the energy can be huge when more PMs are utilized. This will vary when the ineffective servers are switcher off.

\section{Results Analysis}

The experimental setup is already explained the Table 4 and 5 . Considering the Table 1,1000 is said to be the whole number of arrived requests. Also, for VM 125 requests each

Table 6: Types of PMs

\begin{tabular}{|l|l|l|l|l|l|}
\hline $\begin{array}{l}\text { Type of } \\
\text { PM }\end{array}$ & $\begin{array}{l}\text { Storage } \\
\text { (GB) }\end{array}$ & Memory (GB) & CPU & $\begin{array}{l}\mathbf{P}_{\max } \\
\text { (in } \mathbf{~})\end{array}$ & $\begin{array}{l}\mathbf{P}_{\min } \\
\text { (in } \mathbf{~})\end{array}$ \\
\hline Type 1 & 3380 & 30.0 & 16 & 300 & 210 \\
\hline Type 2 & 3380 & 136.8 & 52 & 600 & 420 \\
\hline Type 3 & 3380 & 14.0 & 40 & 500 & 350 \\
\hline
\end{tabular}

The Table 6 gives the different types of $\mathrm{P}_{\min }$ and $\mathrm{P}_{\max }$ for different PMs. 5Slots are set as the mean arrival time. 50 slots are set as the maximum arrival time. 50, 100, 200, 400 and 800 slots are set as the maximum duration of requests. $5 \mathrm{~min}$ is given for each slot. The actual duration can be found as the service time (20) X 5.That is 100minit. Every input, 6 times the simulation is done. The total PMs used both in unused servers switched on and off is shown in Table 7. The Figure 2 shows the comparison of the servers which are idle and off state.

Table 7: Number of used PMs

\begin{tabular}{|c|c|c|c|c|c|c|}
\hline & $\begin{array}{c}\text { MBFD- } \\
\text { O }\end{array}$ & $\begin{array}{c}\text { MBFD- } \\
\text { S }\end{array}$ & $\begin{array}{c}\text { ONWID- } \\
\text { O }\end{array}$ & $\begin{array}{c}\text { ONWID- } \\
\text { S }\end{array}$ & $\begin{array}{c}\text { Prop- } \\
\text { O }\end{array}$ & $\begin{array}{c}\text { Prop- } \\
\text { S }\end{array}$ \\
\hline 50 & 10 & 9 & 9 & 5 & 8 & 5 \\
\hline 100 & 16 & 11 & 17 & 9 & 15 & 9 \\
\hline 200 & 19 & 15 & 20 & 11 & 18 & 11 \\
\hline 400 & 23 & 28 & 24 & 22 & 23 & 21 \\
\hline 800 & 39 & 40 & 40 & 40 & 38 & 39 \\
\hline
\end{tabular}

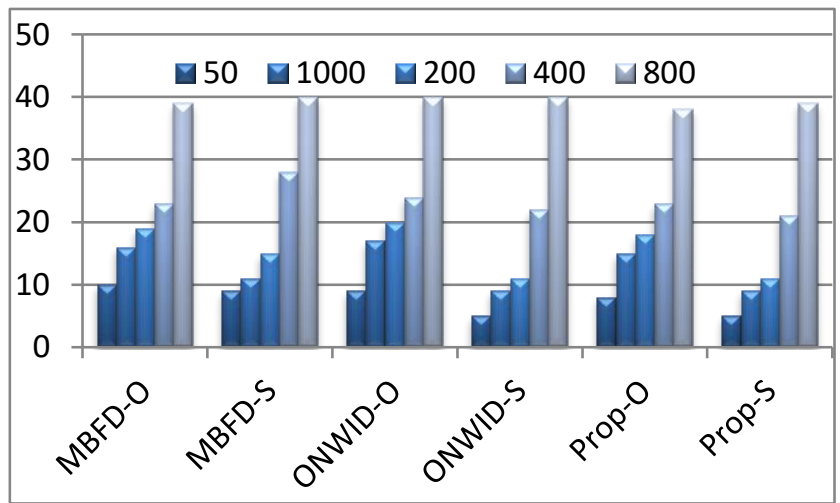

Figure 2: Comparisons of proposed with other algorithms in different state

Figure 2 shows the comparison of the servers which are idle and off state. Here the $-\mathrm{O}$ identifies the Off position and $-\mathrm{S}$ denotes the sleep position of the PMs.

Table 8: Total energy consumption with different requests of VM (Inactive PMs in off mode)

\begin{tabular}{|c|c|c|c|c|}
\hline $\begin{array}{c}\text { Total E con- } \\
\text { sumed in DC } \\
(\mathbf{k W h})\end{array}$ & MBFD & ONWID & Proposed & Migrations \\
\hline maxdur= 50 & 495.1 & 476.0 & 438.4 & 0 \\
\hline maxdur= 100 & 890.8 & 824.7 & 781.7 & 1 \\
\hline maxdur= 200 & 1620.0 & 1492.3 & 1444.4 & 4 \\
\hline maxdur= 400 & 2957.3 & 2762.3 & 2676.0 & 12 \\
\hline maxdur= 800 & 5559.6 & 5209.8 & 5117.2 & 21 \\
\hline
\end{tabular}

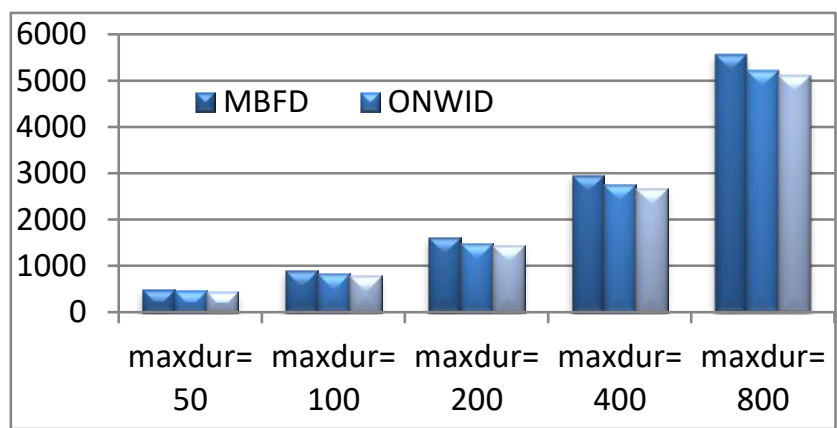

Figure 3: Comparison of energy consumption with different requests of VM (Inactive PMs in off mode)

Figure 3 shows the total energy consumption assuming Inactive PMs are switched off. The number of the migration is given in last column.

Table 9: Total energy consumption when different requests of VMs (Inactive PMs in sleep mode)

\begin{tabular}{|c|c|c|c|c|}
\hline $\begin{array}{c}\text { Total E con- } \\
\text { sumed in DC } \\
(\mathbf{k W h})\end{array}$ & MBFD & ONWID & Proposed & Migrations \\
\hline maxdur= 50 & 1918.4 & 1918.4 & 1918.4 & 0 \\
\hline maxdur=100 & 2797.0 & 2690.7 & 2397.0 & 2 \\
\hline maxdur= 200 & 3411.2 & 3542.4 & 3411.3 & 5 \\
\hline maxdur=400 & 6034.7 & 6034.7 & 6034.7 & 16 \\
\hline maxdur=800 & 9968.7 & 9631.2 & 9568.7 & 30 \\
\hline
\end{tabular}

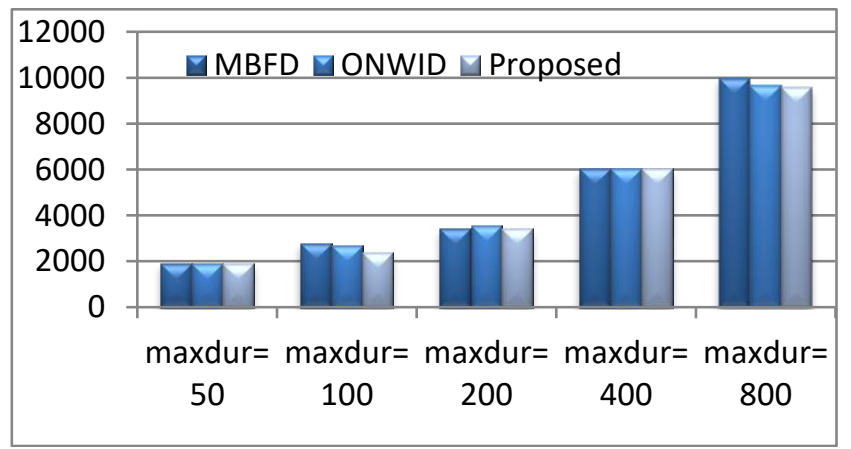

Figure 4: Comparison of energy consumption when different requests of VMs (Inactive PMs in sleep mode)

Table 8 lists the energy consumption of the idle servers when it is in sleep mode. The comparison of the energy is showed in the figure 4. The consumption of the total energy of proposed method is compared with the other algorithms, considering $100 \%$ utilization as the base line. For all the cases, Modified Best Fit Decreasing (MBFD) > ONWID -Online MFF with Delay \& Migration > Proposed the energy consumption in total are calculated applying equation (3) and (7). In general Proposed method consumes 2-4 \% less power compare to MBFD and ONWID. 


\section{Conclusion}

In this paper, a model for reducing the energy consumption is introduced. Here by identifying the active PMs and turning off the idle servers plays a vital role in result. Little improvement in the Watt for each PMs gives more result while considering for the data center. Here the total energy consumption for the all different types of the VMs is calculated. The resource utilization is concerned. Here the algorithms are compared with respect to the switch on mode and the idle mode. Thus by comparing with the existing methods and algorithms this method gives good result. Some of the future work can combine the load balancing and the energy efficiency with the other features together.

\section{References}

[1]. Osama Chaudary, Arfiya S Siddique, "Cloud computing application: its security issues and challenges faced during cloud forensics and investigation", International journal of Advanced research in computer science, Volume 8, No 2, March 2017.

[2]. N. Vyas and A. Chauhan, "A survey on virtual machine migration technique in cloud computing", International Journal of applications Innovation Engineering and management, Volume 5, 297-300. 2016

[3]. L. Youseff," Toward a unified ontology of cloud computing", The proceedings of grid computing environments workshop, GCE, Volume 8, 2012.

[4]. S.Y.Jing, S. Ali, K. She, Y. Zhong," State of art research study for green cloud computing", Journal of Supercomputing, pp 1-24. 2011.

[5]. A. Beloglazov, R. Buyya, Y.C. Lee, A.Y. Zomaya," A taxonomy and survey of energy efficient data centers and cloud computing systems", Advanced Computers, Volume 2, 82,pp 47-111, 2011.

[6]. S. Srikantaiah, A. Kansal, F. Zhao," Energy aware consolidation for cloud computing", Proceedings of USENIX workshop on power aware computing and systems, HotPower, San Diego, CA:USENIX;2008, p 10-4, 2008

[7]. H. Lie, C. Xu,H. Jin, J. Gong, X. Liao," Performance and energy modeling for live migration of virtual machines", the $20^{\text {th }}$ international symposium on high performance distributed computing, pp: 171-182, 2011.

[8]. Lee.Y.C, Zomaya.AY," Energy efficient utilization of resources in cloud computing systems", Journal of supercomputers, Issue 60(2), pp 268-280,2012.

[9]. A. Beloglazov, J.H. Abawajy, R. Buyya," Energy aware resource allocation heuristics for energy efficient management of datacenters for cloud computing". Future Gen Compute Systems, 28(5), 755-768, 2012.

[10]. V. Mathew,R.K. Sitharaman, P.J. Shenoy,” Energy aware load balancing in content delivery networks", Proceedings of IEEE INFOCOM, Orlonado, FL,IEEE, p 954-962, 2012.

[11]. . M. Lin, A. Wierman, L.L.H. Andrew, E. Thereska," Dynamic right-sizing for power propotional data centers", proceedings of IEEE INFOCOM, Shanghai,China, IEEE:2011.p-1098-1106, 2011.

[12]. G.B. Mertzios, M. Shalom, A. Voloshin, P.W.H Wong, S. ZAKS," Optimizing busy time on parallel machines", Proceedings of IPDPS, Shanghai, China: IEEE 2012.p 238-248, 2012

[13]. Amit Agarwal and Jain saloni, "Efficient optimal energy efficient algorithm in cloud computing environment", International journal of computer trends and technology, Volume 9, PP 344349, 2231-2803, 2016

[14]. Gurang patel, Metha, Rutvik and upoi upendra," Enhanced load balancing min-min algorithm", Elsevier B, V, Third international conference on recent trends in computing, PP 545- 553, 1877-0509, 2016.

[15]. G.Soniya Priyatharsini, N.Malarvizhi, "Heuristic Method for cloud resource consolidation with ECRC Algorithm", Journal of Engineering \& Applied sciences, Volume 12(2) (2018) 63256331.

[16]. D. Economou, S. Rivoire, C. Kozyrakis, P. Ranganathan," Full system power analysis and modeling for server environments", Standford University/HP Labs workshop on modeling, benchmarking, and simulation (MoBS), June 182016.

[17]. A. Beloglazov, J. Abawajy, R. Buyya," Energy aware resource allocation heuristics for efficient managements for datacenters for cloud computing", Future Generation Computer systems, 28(5),755-768. 2017.

[18]. Deepa Mehta, Indu kashyap, "Routing optimization in cloud networks", International of advanced research in computer science, volume 8, No 2, March 2017. 